\title{
Chiari malformation and central sleep apnoea: successful therapy with adaptive pressure support servo-ventilation following surgical treatment
}

\author{
Ahmed Fahim, Anthony OC Johnson \\ Department of Respiratory Medicine, Pinderfields Hospital, Mid Yorkshire Hospitals, Wakefield, UK
}

Correspondence to Dr Ahmed Fahim, ahmedfahim@doctors.org.uk

\begin{abstract}
Summary
Sleep apnoea is a common disorder with significant morbidity. It is categorised into obstructive and central sleep apnoea. There are a variety of conditions associated with central sleep apnoea ranging from cardiac failure to structural brain anomalies. We herein report a case of 57-year-old woman with Chiari malformation associated with significant sleep-disordered breathing. There was a family history of Chiari malformation. Although neurosurgical intervention had a significant impact on apnoea hypopnoea index (AHI) with a reduction from $81 / \mathrm{h}$ preoperatively to $22.1 / \mathrm{h}$ after the surgical treatment, it failed to cure the sleep disorder breathing completely and adaptive noninvasive servo-ventilation had a dramatic effect on symptoms and normalised the AHI. Although, central sleep apnoea is associated with a number of common disorders, this case illustrates that there may be an unusual cause. Moreover, adaptive pressure support servoventilation may provide a promising treatment option following surgical correction of Chiari malformation.
\end{abstract}

\section{BACKGROUND}

Sleep-disordered breathing is a significant global health issue. Recent epidemic of obesity has played a significant role in the rise of sleep apnoea. There are two broad categories of sleep apnoea, obstructive and central sleep apnoea. Moreover, a mixture of these categories is frequently encountered. Although obstructive sleep apnoea is a more common variety, central sleep apnoea may be encountered in the context of cardiac failure, acromegaly $^{1}{ }^{2}$ and renal failure. ${ }^{3}$ Herein, we report a case of central sleep apnoea, the aetiology of which is described very rarely. Furthermore, a novel ventilatory strategy following surgical correction has been utilised, which to our knowledge, has not been reported in Chiari malformation before.

\section{CASE PRESENTATION}

A 57-year-old woman was referred to our sleep clinic with a history of snoring and witnessed episodes of apnoea. She also complained of tiredness, lethargy and lack of concentration and motivation. She described waking up coughing as though she was choking. Her snoring was severe; she was restless in bed and woke several times during the night to go to the toilet. Her sleep hygiene was that of a normal pattern and had no problems falling asleep. She denied any orthopnoea or paroxysmal nocturnal dyspnoea. Epworth score was elevated at 18 of 24 .

She was a lifelong non-smoker and consumed minimal amount of alcohol. Basic ear, nose and tongue examination showed a large palate and a crowded pharynx. Her weight was $99.6 \mathrm{~kg}$ with a body mass index of 35.3 . Collar size was measured at $44 \mathrm{~cm}$. There was no evidence of cardiac failure and the rest of the systemic examination was unremarkable.

\section{INVESTIGATIONS AND MANAGEMENT}

Overnight pulse oximetry showed evidence of significant $4 \%$ desaturation rate of $38 / \mathrm{h}$ with minimum and mean oxygen saturation of $75 \%$ and $93 \%$, respectively. This oximetry results in the context of her symptoms supported a diagnosis of severe obstructive sleep apnoea. Hence she was started on a trial of continuous positive airway pressure (CPAP) therapy (Remstar Auto M series CPAP machine). Her compliance was good with an average usage of $6 \mathrm{~h}$ per night every night. However, apnoea hypopnoea index (AHI) remained elevated at 36.7 with a baseline CPAP pressure of $7 \mathrm{~cm} \mathrm{H}_{2} \mathrm{O}$. Epworth score remained elevated at 14/24. In view of the high CPAP pressure required she was started on bilevel positive airway pressure (BIPAP) with a Remstar BIPAP Auto $M$ series machine on auto mode to allow for a higher pressure to be delivered. Inspiratory positive airway pressure (IPAP) and expiratory positive airway pressure were 25 and $10 \mathrm{~cm} \mathrm{H}_{2} \mathrm{O}$, respectively. Despite good compliance with an average usage of $8 \mathrm{~h}$ every night, AHI increased to 52 and symptoms remained persistent. In view of poor response to CPAP and BIPAP, a possibility of central or complex sleep apnoea was considered and a sleep study was performed. The sleep study showed AHI of 81/h with predominantly central apnoeas (99\%). An echocardiogram to evaluate for cardiac failure showed mild pulmonary hypertension in keeping with nocturnal hypoxaemia. However, there was no evidence of ventricular dysfunction.

In view of poor response to CPAP and BIPAP, the patient was started on a trial of adaptive servo-ventilation (ASV). It can treat a mixture of periodic and complex breathing by monitoring and reacting to changes in peak expiratory flow thus preventing cyclical cheyne stoke respiration. Patient reported to be feeling more comfortable on the auto SV as opposed to CPAP therapy. A further 
sleep study while using ASV showed an improvement of AHI to $10.5 / h$ with persistent hypopnoeas.

At next outpatient review, the patient informed that her son had been diagnosed with Arnold-Chiari malformation. In view of an association of Arnold-Chiari malformation with sleep-disordered breathing (specifically central sleep apnoea), an MRI scan of brain (figure 1) was arranged. MRI scan demonstrated significant Chiari type 1 malformation and a syrinx in the spinal cord.

She was referred for neurosurgical intervention and underwent craniocervical decompression for the correction of brain malformation. A follow-up sleep study a couple of weeks after surgical correction, while using ASV, showed complete resolution of sleep apnoea. The patient reported a dramatic improvement in daytime sleepiness and concentration and she was waking up less frequently during the night. To evaluate if the subjective and objective improvement of central sleep apnoea was related to surgical treatment alone, another sleep study was undertaken without ASV. It demonstrated that AHI had increased to 22. Serial sleep studies (table 1) from the outset showed that central sleep apnoea in this patient improved but not cured by surgery alone and ASV had a substantial benefit following surgical correction.

\section{DISCUSSION}

Chiari malformations consist of a downward displacement of the cerebellar tonsils through the foramen magnum and were first described by John Cleland in $1883^{4}$ and subsequently were classified in 1891 into four

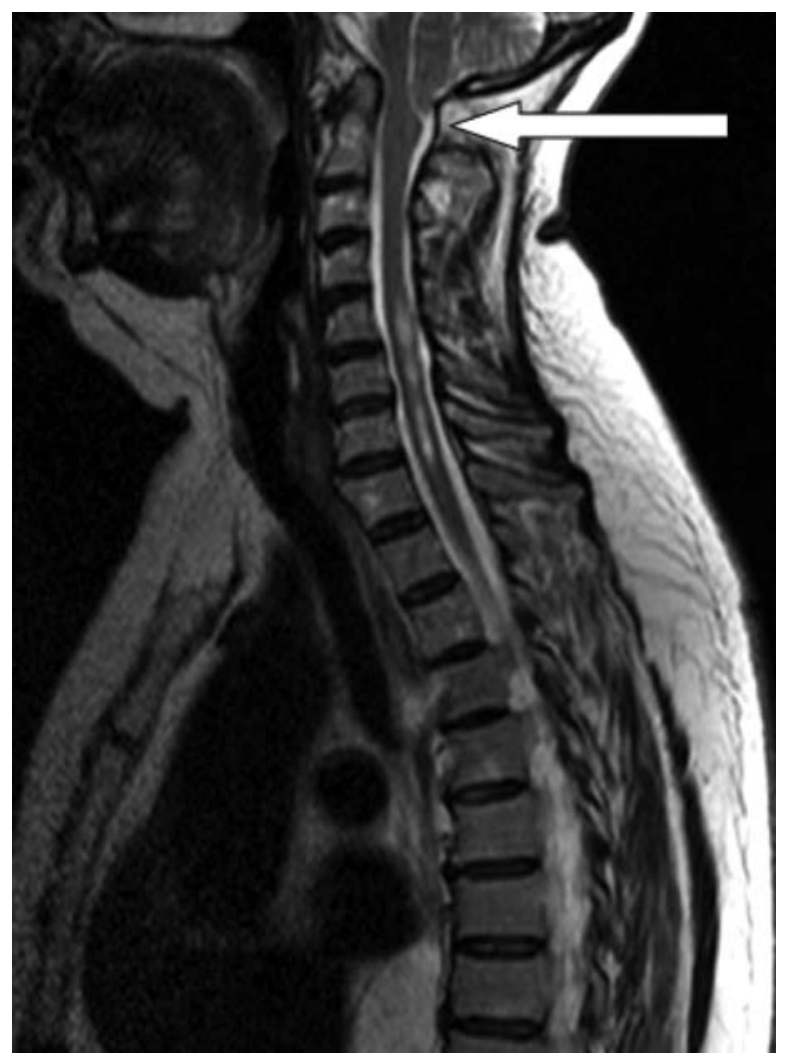

Figure $1 \mathrm{MRI}$ of brain showing downward displacement of cerebellar tonsil (arrow) at the level of foramen magnum consistent with type 1 Chiari malformation.
Table 1 Sleep studies during the course of investigation and management of the patient

\begin{tabular}{lllll}
\hline Measure & Baseline & Auto SV & $\begin{array}{l}\text { Auto SV } \\
\text { postoperation }\end{array}$ & $\begin{array}{l}\text { No NIV } \\
\text { postoperation }\end{array}$ \\
\hline Al & 68 & 0.1 & 0.1 & 8.4 \\
AHI & 81 & 10.5 & 0.7 & 22.1 \\
Total apnoeas & 523 & 1 & 1 & 81 \\
$\quad$ Central & $522(99 \%)$ & $1(100 \%)$ & $1(100 \%)$ & $69(85 \%)$ \\
$\quad$ Obstructive & $1(0 \%)$ & 0 & 0 & $3(4 \%)$ \\
$\quad$ Mixed & 0 & 0 & 0 & $9(11 \%)$ \\
Hypopnoeas & 103 & 105 & 7 & 132 \\
Duration mean & $23(46)$ & $16(48)$ & $14(18)$ & $17(59)$ \\
(max) & & & $94 \%$ & $93 \%$ \\
Mean Sp0 & $91 \%$ & $95 \%$ & $94 \%$ & 39.5 \\
4\% Dip rate & 79 & 35 & 9.6 & \\
\hline
\end{tabular}

AHI, apnoea hypopnea index; Al, apnoea index; NIV, non-invasive ventilation; SV, servo-ventilation.

groups. ${ }^{5}$ Type 1 Chiari malformation is the most common variety with caudal prolapse of cerebellar tonsils to the level of upper cervical spinal canal. Type 2 malformation is a more severe form with displacement of cerebellar vermis and tonsils and a spinal myelomeningocele. ${ }^{6}$ Type 3 is rare and is associated with a high cervical or occipital encephalocele along with inferior displacement of brainstem into the spinal canal. Type 4 refers to cerebellar hypoplasia without significant relation to other Chiari malformations. There have been a handful of cases of central sleep apnoea in relation to Chiari malformation. ${ }^{7-9}$ The exact mechanism of sleep disordered breathing secondary to this malformation is not known to a great extent. However, it may either be related to upper airway dysfunction resulting in obstructive sleep apnoea or disruption of central respiratory drive manifesting as central sleep apnoea. Furthermore, mechanical effects of cerebellar herniation on respiratory centre in medulla may be another mechanism of sleep-related apnoeic spells in this disorder.

This case demonstrates the effectiveness of servo-assisted ventilation in a patient with severe central sleep apnoea in association with brain malformation. The patient described in this case report had minimal subjective and objective benefit by CPAP or BIPAP mode of non-invasive ventilation prior to surgical treatment of Chiari malformation. In view of the failed trial of these ventilatory modes, ASV trial was attempted. ASV is a mode of ventilation with automated sensing of normal breaths and assures to avoid artificial ventilation during the periods of normal breaths. Hence, it results in minimising the likelihood of cyclical or ataxic breathing and is considered a novel mode of ventilation in selected cases of sleep apnoea. There is evidence of effectiveness of ASV in opioids-induced central sleep apnoea ${ }^{10}$; however, its effectiveness in complex sleep apnoea and mixed apnoeas is not known to a great extent.

In conclusion, this case highlights the importance of considering structural brain disorders as a cause of sleep-disordered breathing particularly if there is a family history of brain malformation and a poor response to initial CPAP therapy. Moreover, it highlights the effectiveness of ASV in treating central sleep apnoea related to Chiari malformation following surgical correction, which to our knowledge has never been reported in the literature before. 


\section{Learning points}

- Chiari malformation may present as central sleep apnoea particularly if there is a family history of this structural brain disorder.

- Sleep-disordered breathing associated with Chiari malformation may be resistant to conventional mode of ventilation that is, continuous positive airway pressure and bilevel positive airway pressure.

- Surgical correction of the brain anomaly along with adaptive pressure support servo-ventilation offers a promising treatment option with immediate improvement in daytime sleepiness and apnoea hypopnoea index.

\section{Competing interests None}

Patient consent Obtained.

\section{REFERENCES}

1. Grunstein RR, Ho KY, Sullivan CE. Sleep apnea in acromegaly. Ann Intern Med 1991:115:527-32.
2. Grunstein RR, Ho KY, Berthon-Jones M, et al. Central sleep apnea is associated with increased ventilatory response to carbon dioxide and hypersecretion of growth hormone in patients with acromegaly. Am $\mathrm{J}$ Respir Crit Care Med 1994;150:496-502.

3. Venmans BJ, van Kralingen KW, Chandi DD, et al. Sleep complaints and sleep disordered breathing in hemodialysis patients. Neth $\mathrm{J}$ Med 1999;54:207-12.

4. Carmel PW, Markesbery WR. Early descriptions of the Arnold-Chiari malformation. The contribution of John Cleland. J Neurosurg 1972;37:543-7.

5. Sarnat HB. Disorders of segmentation of the neural tube: Chiari malformations. Handb Clin Neurol 2008;87:89-103.

6. Omer S, al Kawi MZ, Bohlega S, et al. Respiratory arrest: a complication of Arnold-Chiari malformation in adults. Eur Neurol 1996;36:36-8.

7. Rabec C, Laurent G, Baudouin N, et al. Central sleep apnoea in Arnold-Chiari malformation: evidence of pathophysiological heterogeneity. Eur Respir J 1998;12:1482-5.

8. Adam N, Luiza J, Robert P, et al. Sleep apnoea related to Arnold-Chiari malformation. Pneumonol Alergol Pol 2004;72:530-2.

9. Spence J, Pasterkamp H, McDonald PJ. Isolated central sleep apnea in type I Chiari malformation: improvement after surgery. Pediatr Pulmonol 2010;45:1141-4.

10. Javaheri S, Malik A, Smith J, et al. Adaptive pressure support servoventilation: a novel treatment for sleep apnea associated with use of opioids. J Clin Sleep Med 2008;4:305-10.

Copyright 2012 BMJ Publishing Group. All rights reserved. For permission to reuse any of this content visit http://group.bmj.com/group/rights-licensing/permissions.

BMJ Case Report Fellows may re-use this article for personal use and teaching without any further permission.

Please cite this article as follows (you will need to access the article online to obtain the date of publication).

Fahim A, Johnson AOC. Chiari malformation and central sleep apnoea: successful therapy with adaptive pressure support servo-ventilation following surgical treatment. BMJ Case Reports 2012;10.1136/bcr-2012-007143, Published XXX

Become a Fellow of BMJ Case Reports today and you can:

- Submit as many cases as you like

- Enjoy fast sympathetic peer review and rapid publication of accepted articles

- Access all the published articles

- Re-use any of the published material for personal use and teaching without further permission

For information on Institutional Fellowships contact consortiasales@bmjgroup.com

Visit casereports.bmj.com for more articles like this and to become a Fellow 